\title{
What is the Best Needle for Spinal Thoracic Anesthesia: Pencil Point Needle or Cut Point Needle? Letter to Editor
}

\section{Luiz Eduardo Imbelloni*}

Anesthesiologist of Hospital Clínicas Municipal São Bernardo do Campo, São

Bernardo do Campo, SP, Brazil

*Corresponding Author: Luiz Eduardo Imbelloni, Anesthesiologist of Hospital

Clínicas Municipal São Bernardo do Campo, São Bernardo do Campo, SP, Brazil.
Received: April 20, 2020

Published: June 19, 2020

(C) All rights are reserved by Luiz Eduardo Imbelloni.
We recently demonstrated the safety of thoracic spinal anesthesia by the study with MRI in 50 patients [1]. In order to verify the incidence of neurological complications in spinal thoracic anesthesia, a study was carried out comparing the two most frequently used needles (Cut vs Point Pencil) in 300 patients divided into two groups of 150 patients, puncture success was observed in all patients with $20(6.6 \%)$ paresthesia with no significant difference between the needles [2]. All paresthesia were transient and no neurologic complications were observed. In 2012, we conducted a study of 636 patients undergoing spinal thoracic anesthesia in different types of surgery (laparoscopic cholecystectomy, herniorrhaphy, urologic, gynecologic and orthopedic surgeries) with hyperbaric or isobaric bupivacaine, showing that low doses of local anesthetics ( 5 to $10 \mathrm{mg}$ ) and thoracic puncture reduce the latency time, the degree of motor block and cardiocirculatory changes, without neurological complications [3].

Despite the anatomical evidence obtained with MRI [1] and the clinical application of thoracic spinal anesthesia [2,3], the vast majority of anesthesiologists remain reluctant to perform thoracic puncture, despite systematically performing thoracic epidural surgery for plastic surgery $(1,240$ patients $)$ with accidental perforation in 4 patients $(0.3 \%)$, however without direct injury to the spinal cord [4].

In 1909, Thomas Jonnesco carried out a study in proposed the use of general spinal block for surgeries of the skull, head, neck, and thorax [5]. He performed punctures between the $1^{\text {st }}$ and 2 nd thoracic vertebrae (103 patients), which produced perfect and deep analgesia for the body segment including the head, neck, and upper limbs. Since middle thoracic puncture, between the $7^{\text {th }}$ and 8th vertebrae, was more difficult to accomplish and unnecessary for surgeries of the lower thoracic segment, he performed the puncture between the $12^{\text {th }}$ thoracic vertebra and the 1 st lumbar vertebra (295 patients), which was easily accomplished and pro- duced anesthesia for the lower portion of the body. The segmental spinal anesthesia of the lower thoracic was introduced in 1954 [6].

Studying 20 patients who underwent laparoscopic cholecystectomy through the combined spinal epidural block using the $27 \mathrm{G}$ pencil point, despite I use both needles (cut point or pencil point) $[2,3]$ I prefer to use the cutting point needle because it has its terminal hole.

The 25G new pencil-point needle has an internal diameter of $0.32 \mathrm{~mm}$ which can provide a quick appearance of CSF flow [8]. The lateral orifice of this needle starts at $0.8 \mathrm{~mm}$ and ends only at 1.7 $\mathrm{mm}$, so there is a need to penetrate into the subarachnoid space $2 \mathrm{~mm}$ for the CSF to appear. Due to this penetration of more than $2 \mathrm{~mm}$, the authors described a high incidence of paresthesia [9]. Because the cutting needles have their terminal hole (and not lateral like the atraumatic needles), the appearance of the CSF is immediately after the puncture of the subarachnoid space. This way makes it safer to risk the insertion of the needle without damage to the cord.

In seven women ( 6 obstetric and 1 surgical) submitted to combined spinal-epidural block with pencil point needles (25G and $27 \mathrm{G}$ ) all experienced pain during insertion of the needle, which at the L2-L3 interspace, was followed by neurological symptoms involving more than one segmental nerve root diagnosed by MRI [10].

The spinal needles used during puncture for spinal anesthesia produced lesions in the dura with different morphology and characteristics. Studying with scanning electron microscopy in vitro the lesions produced by $25 \mathrm{G}$ needles cut point and pencil point showed that the lesions produced by the cut needle resulting in a clean-cut opening in the dural membrane while the Whitacre needle produced a more traumatic opening with tearing and severe disruption of the collagen fibers [11]. 
The hole left in the dura mater by the pencil point needle can probably cause less leakage of CSF, but giving it in direct contact with the spinal cord can generate more damage. In Brazil, due to the price, the cutting needle is more used than the pencil tip, which does not happen in obstetrics. Without good comparative data it is impossible to say whether one type of needle is more likely to be associated with spinal cord problems.

In 1909 Jonnesco write [4]: "The needle I prefer has a point cut rather squarely, for since the arachnoid space is relatively small, if the point of the needle be oblique, it is possible that part of the opining might go through the dura mater while part remained outside $i t$ ". What a look! He not only used a thoracic spinal anesthesia and the cut needle. The various reports described of spinal cord injury with pencil point needles, suggest that due to the need to penetrate more than $2 \mathrm{~mm}$ into the subarachnoid space, it can result in conus damage. This is one more reason to prefer the cutting bevel of the Quincke needle for low thoracic spinal anesthesia.

\section{Bibliography}

1. Imbelloni LE., et al. "The anatomy of the thoracic spinal canal investigated with magnetic resonance imaging". Anesthesia and Analgesia 110.5 (2010): 1494-1495.

2. Imbelloni LE., et al. "The Incidence of Paresthesia and neurologic complications after lower spinal thoracic puncture with cut needle Compared to pencil point needle. Study in 300 patients". Journal of Anesthesia and Clinical Research 1.2 (2010): 106.

3. Imbelloni LE., et al. "Thoracic spinal anesthesia with low doses of local anesthetic decreases the latency time, motor block and cardiovascular changes. Study in 636 patients". Journal of Anesthesia and Clinical Research S11 (2011): 001.

4. Leão DG. "Thoracic epidural anesthesia: Analysis of 1240 cases”. Revista Brasileira de Anestesiologia 47 (1997): 138-147.

5. Jonnesco T. “General spinal analgesia”. British Medical Journal 2 (1909): 1396-1401.

6. Frumin MJ., et al. "Dorsal root ganglion blockade during threshold segmental spinal anesthesia in man". Journal of Pharmacology and Experimental Therapeutics 112.3 (1954): 387-392.

7. van Zundert AAJ., et al. "Laparoscopic cholecystectomy under segmental thoracic spinal anaesthesia: a feasibility study". British Journal of Anaesthesia 98.5 (2007): 682-686.
8. Krommendijk EJ., et al. "The pencan 25-gauge needle: A new pencil-point for spinal anesthesia tested in 1,193 patients". Regional Anesthesia and Pain Medicine 24.1 (1999): 43-50.

9. Turner MA and Shaw M. "Atraumatic spinal needles". Anaesthesia 48.5 (1993): 452.

10. Reynolds F. "Damage to the conus medullaris following spinal anaesthesia". Anaesthesia 56.3 (2001): 238-247.

11. Reina MA., et al. "An in vitro study of dural lesions produced by 25-gauge Quincke and Whitacre needles evaluated by scanning electron microscopy". Regional Anesthesia and Pain Medicine 25.4 (2000): 393-402.

\section{Assets from publication with us}

- Prompt Acknowledgement after receiving the article

- Thorough Double blinded peer review

- Rapid Publication

- Issue of Publication Certificate

- High visibility of your Published work

Website: www.actascientific.com/

Submit Article: www.actascientific.com/submission.php Email us: editor@actascientific.com

Contact us: +919182824667 